\title{
FATORES DE SUCESSO EM MODELOS DE NEGÓCIOS CIRCULARES: UMA REVISÃO SISTEMÁTICA
}

Matheus Bragalia Rodrigues (matheus.bragalia.rodrigues@usp.br) - Escola de Engenharia de São Carlos, Universidade de São Paulo (USP).

Camila Gonçalves Castro (camilagcastro@usp.br) - Escola de Engenharia de São Carlos, Universidade de São Paulo (USP).

Janaina Mascarenhas Hornos da Costa (jana.mascarenhas@usp.br) - Escola de Engenharia de São Carlos, Universidade de São Paulo (USP).

\section{RESUMO}

A possibilidade de transição para um modelo econômico alternativo, como é o caso da Economia Circular, surge em um panorama mundial marcado pelo consumo desenfreado, aumento das disparidades socioeconômicas e destruição do meio ambiente. A partir do momento em que Modelos de Negócios passam a adotar os princípios da Economia Circular, buscando novas formas de criar valor, é possível gerar impacto positivo nos três pilares do desenvolvimento sustentável: social, econômico e ambiental. Este trabalho tem como objetivo principal identificar quais são os fatores que levam os Modelos de Negócios que aplicam os princípios da Economia Circular (Modelos de Negócios Circulares) a obterem sucesso, isto é, criar novas formas de geração de valor e causar impacto positivo na sociedade, economia e meio ambiente. Através da execução de uma Revisão Bibliográfica Sistemática, que possibilitou a criação de filtros e critérios de seleção específicos, foi possível levantar 25 artigos que resultaram em 31 estudos de casos de Modelos de Negócios Circulares de sucesso para serem analisados. Como principal resultado, esta pesquisa apresenta os principais Fatores de Sucesso de Modelos de Negócios Circulares classificados em 6 dimensões específicas encontradas na literatura: Organizacional e Estratégica, Externa, Tecnológica, Econômica e Financeira, Social e Institucional.

Palavras-chave: economia circular, modelos de negócios circulares, fatores de sucesso, estudos de caso, revisão sistemática. 


\section{INTRODUÇÃO}

A Economia Circular (EC) tem se mostrado promissora ao possibilitar a reversão da lógica de consumo atual e a geração de impacto positivo nos pilares social, econômico e ambiental. Além disso, a EC também tem sido aplicada e alavancada pelos mais diversos tipos de Modelos de Negócios (MN) ao redor do mundo: são os chamados Modelos de Negócios Circulares (MNC).

O debate relativo ao conceito de EC e a sua aplicação em novos MN ou em MN já existentes se intensificou nos últimos anos, o que tem atraído cada vez mais o interesse de pesquisadores e praticantes diversos (CENTOBELLI et al., 2020). Por outro lado, a literatura ainda carece de estudos que identifiquem e classifiquem de maneira sistemática os principais Fatores de Sucesso (FS) de iniciativas de EC no mundo dos negócios (ALOINI et al., 2020). As pesquisas existentes ainda estão longe de possibilitarem uma compreensão profunda sobre como as companhias podem estruturar os seus $\mathrm{MN}$ e gerar valor em coerência com os princípios da EC, o que revela a necessidade pela busca das principais implicações da EC em indústrias e setores de mercado específicos (DEL VECCHIO et al., 2021).

Este estudo se faz relevante na medida em que contribui com a identificação de fatores que levam MNC a obterem sucesso ao criarem novas formas de geração de valor, sob a ótica de estudos de casos reais em setores de mercado, níveis de maturidade e contextos diversificados.

Por fim, este trabalho tem como objetivo geral identificar quais são os fatores que levam os MNC a obterem sucesso e classificá-los de acordo com dimensões específicas identificadas na literatura.

\section{REVISÃO TEÓRICA}

No contexto de aplicação dos MNC, os FS são aqueles que favorecem a aplicação prática dos princípios da EC. Um MNC atinge o sucesso quando cria novas formas de geração de valor e causa impacto positivo social, econômico e ambiental. Segundo Aloini et al. (2020), a importância do entendimento de FS ligados a EC pode auxiliar organizações empresariais a amplificar o impacto de suas iniciativas, ao mesmo tempo em que pode servir de referência para autoridades públicas criarem novos incentivos e legislações. Além disso, a identificação de FS pode contribuir diretamente com a transição para a EC, na medida em que fornece insights importantes sobre diferentes graus de iniciação, manutenção e sucesso dos MNC (ALOINI et al., 2020). 
Com base em múltiplas referências, Aloini et al. (2020) propuseram dimensões para que fosse possível analisar e classificar quais capabilidades e/ou condições podem apoiar o processo de implementação de MNC, ilustradas na figura 1:

\begin{tabular}{|c|c|}
\hline Dimensão & Subdimensão e Fatores de Sucesso \\
\hline \multirow[b]{2}{*}{ Institucional } & Incentivos e regulamentações: políticas, leis, diretivos e regulamentações \\
\hline & $\begin{array}{l}\text { Apoio: cortes de taxação, politicas de restituição, financiamento e empréstimos governamentais a juros baixos, politica de subsídios, incentivos fiscais para } \\
\text { soluções sustentáveis }\end{array}$ \\
\hline \multirow{2}{*}{ Econômica e Financeira } & $\begin{array}{l}\text { Potencial econômico e financeiro: uso e recuperação eficaz dos recursos disponíveis, redução de custos, maior lucratividade a partir do uso circular dos } \\
\text { recursos, alta performance diante dos competidores, acesso a financiamento privado, consistência entre geração de receita/redução de custos e investimentos } \\
\text { necessários }\end{array}$ \\
\hline & $\begin{array}{l}\text { Potencial para o desenvolvimento de novos negócios e inovação: criação de novas percepções de valor, acesso a mercados recentes, mercados verdes ou } \\
\text { outros nichos de mercado }\end{array}$ \\
\hline \multirow[b]{2}{*}{ Tecnológica } & Tecnologias digitais: tecnologias digitais da informação e comunicação, inteligência artificial, internet das coisas (IoT), automação \\
\hline & $\begin{array}{l}\text { Tecnologias voltadas aos 3Rs (Reduzir, Reciclar e Reutilizar): produtos tecnológicos e processos inovadores voltados à redução, reciclagem ou reutilização } \\
\text { de produtos e materiais }\end{array}$ \\
\hline \multirow{4}{*}{$\begin{array}{l}\text { Organizacionale } \\
\text { Estratégica }\end{array}$} & $\begin{array}{l}\text { Modelo de negócio voltado a EC: intensificação do "green marketing", desenvolvimento de mercado secundário de alto valor, manufatura redistribuida, } \\
\text { "green purchasing", sistemas de gestão e certificação voltados a EC e sustentabilidade }\end{array}$ \\
\hline & Cultura organizacional: confiança e abertura, cultura e consciência voltadas a EC e sustentabilidade \\
\hline & $\begin{array}{l}\text { Questões estratégicas: reputação e responsabilidade social da marca, resiliência do modelo de negócio, estratégia corporativa com foco na EC e } \\
\text { sustentabilidade, mudança para um modelo de negócio sustentável e competitivo, qualidade dos produtos e serviços circulares oferecidos, potencial de } \\
\text { diferenciação }\end{array}$ \\
\hline & $\begin{array}{l}\text { Skills e capabilidades voltados a EC: know-how dos colaboradores e da organização, treinamento e educação voltados a EC, envolvimento e motivação dos } \\
\text { colaboradores em relação a EC e sustentabilidade, conhecimento sobre impactos ambientais, conhecimento de mercado }\end{array}$ \\
\hline \multirow{2}{*}{ Social } & Pressão global: pressão voltada a práticas verdes e mais sustentáveis vindas de entidades públicas, competidores e sociedade \\
\hline & $\begin{array}{l}\text { Conscientização dos consumidores: consciência acerca da EC e sustentabilidade, mudança de preferências de consumo, possessão e utilização de produtos e } \\
\text { serviços }\end{array}$ \\
\hline \multirow{2}{*}{ Externa } & $\begin{array}{l}\text { Comunicação e colaboração: colaboração, parceria ou coordenação com stakeholders externos (consumidores. fornecedores, organizações, ONGs, governo) } \\
\text { através de networking ou compartilhamento de informações, práticas de comunicação, desenvolvimento conjunto de produtos e capabilidades, responsabilidade } \\
\text { compartilhada pela implementação da EC ao longo da cadcia de suprimentos }\end{array}$ \\
\hline & $\begin{array}{l}\text { Configuração da cadeia de suprimentos: múltiplos canais de distribuição, integração da cadeia de suprimentos, gestão da cadeia de suprimentos, estrutura do } \\
\text { mercado de abastecimento, potencial para redução da dependência logística e evitar preços altos e voláteis, capacidade de interconexão possibilitada pela } \\
\text { proximidade geográfica, redesign da cadeia logística }\end{array}$ \\
\hline
\end{tabular}

FIGURA 1 - Fatores de Sucesso para os Modelos de Negócios Circulares. Fonte: adaptado de Aloini et al.,

Nos MN, a incorporação dos princípios da EC acontece em diferentes níveis e está relacionada a diferentes motivações por parte dos seus fundadores, visto que ela é dependente das ambições dos tomadores de decisão e das estratégias adotadas por eles (PIERONI; MCALOONE; PIGOSSO, 2019). Segundo Rovanto e Bask (2021), podemos classificar os níveis de maturidade relativos aos princípios da EC nos MN de duas formas diferentes:

- Modelos de Negócios Circulares Nativos (MNCN): são companhias relativamente jovens, com MN iniciais baseados nos princípios da EC desde o seu início; 
- Modelos de Negócios Circulares Em Transição (MNCT): são companhias maduras que surgiram durante a predominância da EL e que têm criado esforços para implementar a EC e seus princípios em seus MN existentes.

\section{METODOLOGIA}

A Revisão Bibliográfica Sistemática (RBS) foi a metodologia de pesquisa selecionada para a execução deste trabalho, buscando facilitar a identificação de elementos comuns entre os estudos de casos práticos relacionados a MNC já existentes. A abordagem sistemática significa ainda utilizar um método iterativo, que segue macro e micro etapas específicas (figura 2) que permitem a sua repetição por meio de ciclos de maneira contínua, de modo que seja possível alcançar o(s) objetivo(s) da revisão (CONFORTO; AMARAL; SILVA, 2011).
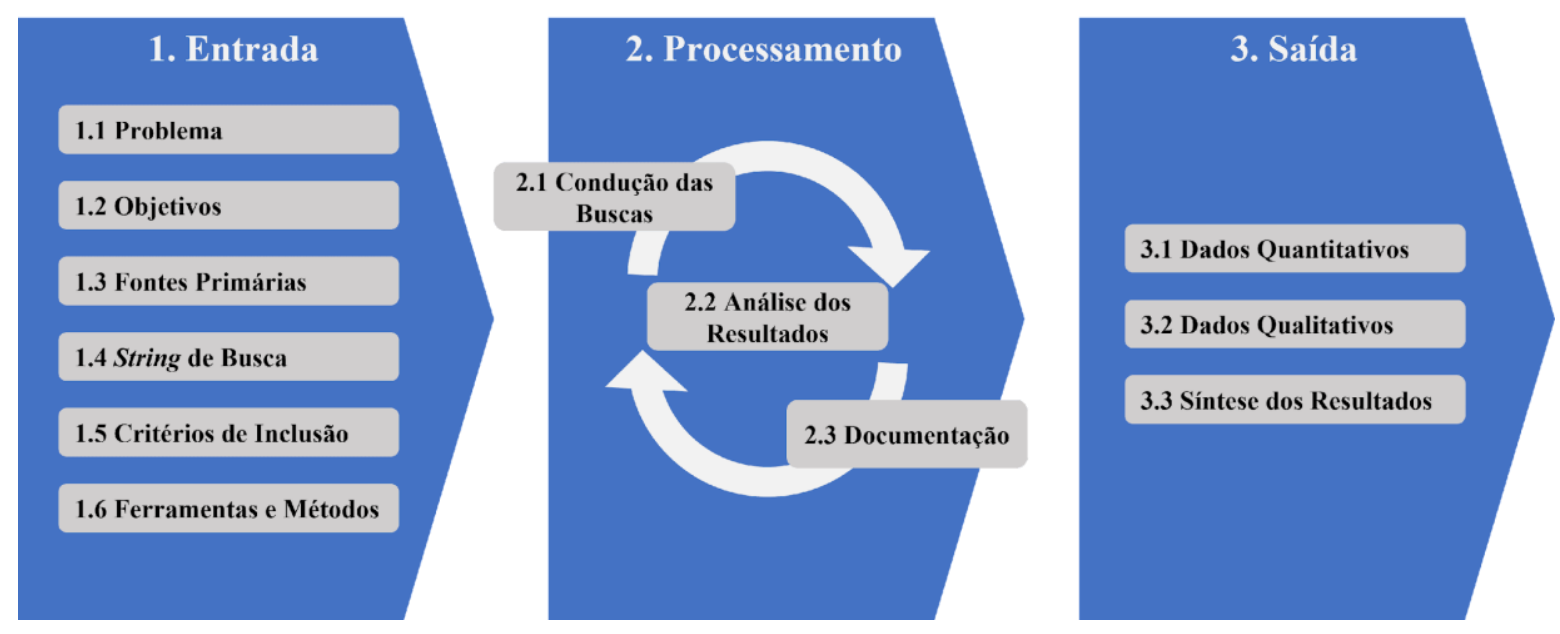

FIGURA 2 - Fases da Revisão Bibliográfica Sistemática. Fonte: adaptado de Conforto, Amaral e Silva, (2011)

Para guiar este trabalho foi definida a seguinte pergunta de pesquisa: "Quais são os fatores que asseguram o sucesso da aplicação dos princípios da Economia Circular nos Modelos de Negócios Circulares?”. Para este estudo, buscou-se selecionar apenas artigos que utilizem como método o estudo de caso. Através de estudos empíricos de diferentes setores de mercado, é possível entender como as organizações estão estruturando os seus Modelos de Negócios a partir da perspectiva da Economia Circular, levando em consideração os fatores que levaram tais iniciativas a alcançarem o sucesso (DE MATTOS; DE ALBUQUERQUE, 2018).

Com esta definição foi possível estabelecer as palavras-chave para a condução das buscas, sendo que as plataformas utilizadas foram o Scopus e Web of Science. As strings 
elaboradas para ambas as plataformas de busca continham as seguintes palavras-chave e estrutura: "circular economy" AND "business model" AND "case study".

Os documentos obtidos foram analisados seguindo dois filtros diferentes. O primeiro deles consistiu na leitura do título, resumo e palavras-chave dos artigos, considerando os seguintes critérios de inclusão: os trabalhos devem abordar estudos de caso de Modelos de Negócios relacionados a Economia Circular; devem estar no idioma inglês; devem estar disponíveis para consulta. Por fim, o segundo filtro consistiu na leitura completa dos artigos, com os seguintes critérios de inclusão: os trabalhos abordados devem realizar estudos empíricos; os casos analisados devem fazer menção aos Fatores de Sucesso das iniciativas em questão.

A figura 3 representa o processo de condução das buscas e filtragem dos artigos, até a obtenção da amostra final.

Bases de dados: Scopus e WoS String de busca: TITLE-ABS-KEY

("circular-economy" AND "businessmodel" AND "case-study") Data: 14.03 .2021

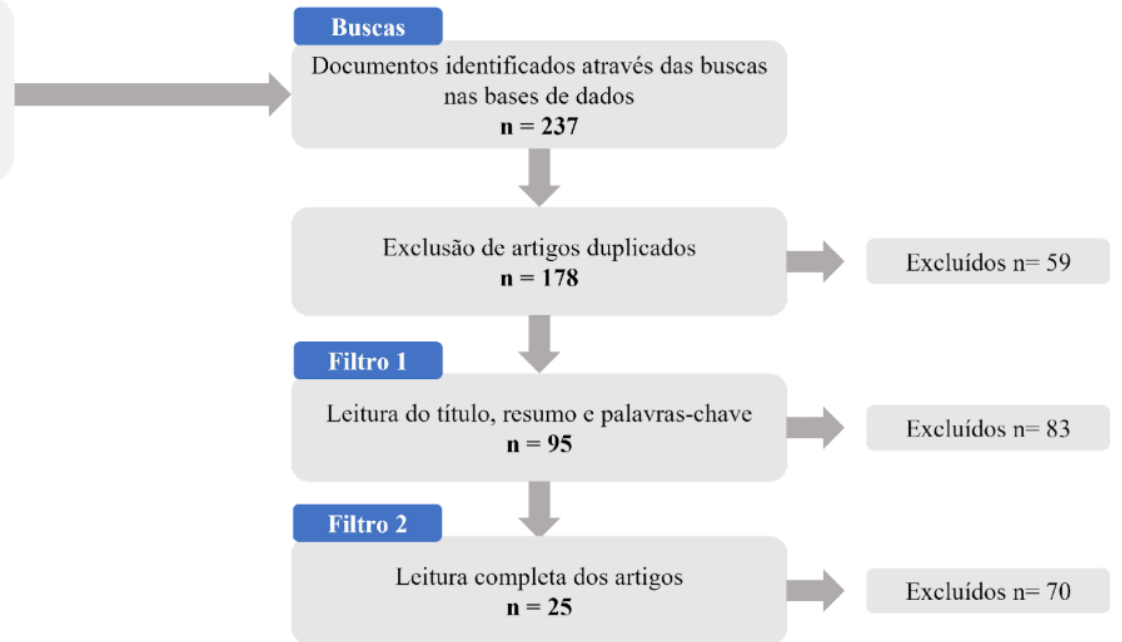

FIGURA 3 - Resumo da RBS executada. Fonte: elaborado pelo autor

\section{RESULTADOS E DISCUSSÃO}

Os 25 artigos selecionados para análise resultaram em 31 estudos de caso, uma vez que a seleção contemplou artigos que utilizaram "múltiplos estudos de caso" como método de pesquisa. As principais informações sobre os estudos de caso foram sintetizadas na figura 4. 


\begin{tabular}{|c|c|c|c|c|}
\hline ID & Setor de mercado & $\begin{array}{l}\text { MNCN ou } \\
\text { MNCT? }\end{array}$ & Descrição do caso & Ano \\
\hline 1 & Têxtil & MNCT & $\begin{array}{l}\text { Marca de roupas femininas que criou um programa de arrecadação e restauração de peças que } \\
\text { não são mais utilizadas pelos seus clientes }\end{array}$ & 2019 \\
\hline 2 & Tecnologia & $\mathrm{MNCN}$ & $\begin{array}{l}\text { Enquresa que oferece soluçōes escaláveis para acelerar a reutilização e reciclagem de produtos } \\
\text { através da criaçâo de e-commerces de mercados de segunda-mão }\end{array}$ & 2016 \\
\hline 3 & Tecnologia & MNCT & $\begin{array}{l}\text { Empresa global do ramo de tecnologia voltada a sistemas, produtos, serviços e aplicą̧̃es digitais } \\
\text { que desenvolveu uma "cabine de controle digital" que possibilita uma visão sistêmica de todos } \\
\text { os processos daplanta da fábrica }\end{array}$ & 2018 \\
\hline 4 & $\begin{array}{l}\text { Serviços de reciclagem, } \\
\text { restauração e gestão de } \\
\text { resíduos }\end{array}$ & MNCT & $\begin{array}{l}\text { O core business do modelo de negócio está atrelado ao oferecimento de serviços de reciclagem } \\
\text { de materiais e tratamento de água e solo personalizados. }\end{array}$ & 2020 \\
\hline 5.1 & Eletrodomésticos & $\mathrm{MNCN}$ & $\begin{array}{l}\text { Uma startup do tipo "Product as a Service" que oferece máquinas de lavar por assinatura mensal } \\
\text { oupor ciclo de lavagem }\end{array}$ & \multirow{3}{*}{2018} \\
\hline 5.2 & Eletrodomésticos & MNCT & $\begin{array}{l}\text { Distribuidor de peças de eletrodomésticos em mais de } 70 \text { paises e que também oferece serviços de } \\
\text { assistência técnica especializada }\end{array}$ & \\
\hline 53 & Eletrodomésticos & MNCT & $\begin{array}{l}\text { "Selj service" de lavagem de roupas, no modelo de franquias, em que o diferencial é a } \\
\text { digitalização da experiência do consumidor }\end{array}$ & \\
\hline 6 & Agronegócio & $\mathrm{MNCN}$ & Empresa que utiliza efluentes domésticos e resíduos orgâricos para produzir fertilizartes agricolas & 2019 \\
\hline 7.1 & Tecnologia & $\mathrm{MNCN}$ & $\begin{array}{l}\text { Empresa que produz veículos automotivos a base de hidrogênio e os oferta através do modelo de } \\
\text { "Product as a Service" }\end{array}$ & \multirow{3}{*}{2021} \\
\hline 7.2 & Tecnologia & $\mathrm{MNCN}$ & $\begin{array}{l}\text { Empresa que oferece serviços voltados a rodovias e estradas de ferro com base em soluçōes de } \\
\text { IoT }\end{array}$ & \\
\hline 73 & Sistemas de ihıminação & $\mathrm{MNCN}$ & $\begin{array}{l}\text { Empresa que oferece um serviço de "light as service ", no qual já estão inclusos os custos de } \\
\text { instalaçăo, manutenção e reparo do sistema de iluminaçẵo }\end{array}$ & \\
\hline 8 & Turismo & MNCN & Plataforma digital de turismo sustentável em que os usuários podem divulgar as suas locações & 2021 \\
\hline 9 & Indústria automotiva & MNCT & $\begin{array}{l}\text { Enturesa de veículos que passou a oferecer um programa exclusivo de incentivo a utilização de } \\
\text { peças remanufaturadas }\end{array}$ & 2020 \\
\hline 10 & Indústria de calçados & $\mathrm{MNCN}$ & $\begin{array}{l}\text { F abric ante de calçados que tarmbém promove a renovação dos mesmos, além de oferecer serviços } \\
\text { de limpeza e personalizaça o dos produtos }\end{array}$ & 2020 \\
\hline 11 & Bens de consumo & MNCT & $\begin{array}{l}\text { Companhia de bens de consumo que passou a incorporar práticas da } \mathrm{EC} \text { em seu modelo de } \\
\text { negócio, buscando zerar a gerafăo de residuos ao longo da cadeia produtiva }\end{array}$ & 2019 \\
\hline 12 & Construção civil & MNCT & $\begin{array}{l}\text { Empresa que realiza a venda tacos e carpetes de madeira que passou a explorar a criaçäo de novas } \\
\text { fontes de valor para seus prochtos com foco na sustentabilidade }\end{array}$ & 2019 \\
\hline 13.1 & $\begin{array}{l}\text { Serviços de reciclagem, } \\
\text { restauração e gestão de } \\
\text { resíduos }\end{array}$ & MNCN & $\begin{array}{l}\text { Empresa que busca fornecer soluçöes inovadoras de logística reversa para a indústria de } \\
\text { eletrodomésticos de linha branca }\end{array}$ & \multirow[b]{2}{*}{2018} \\
\hline 13.2 & $\begin{array}{l}\text { Serviços de reciclagem, } \\
\text { restauração e gestão de } \\
\text { resíduos }\end{array}$ & $\mathrm{MNCN}$ & $\begin{array}{l}\text { Empresa que oferece como serviço a coleta e transformação de eletroeletrônicos e seus } \\
\text { componentes emnovos materiais e inputs para o processo produtivo }\end{array}$ & \\
\hline 14 & Indústria de jóias & MNCT & $\begin{array}{l}\text { Joalheria tradicional que passou a oferecer serviços de manutenção pós-compra e de reciclagem } \\
\text { de seus produtos }\end{array}$ & 2020 \\
\hline 15 & Varejo de alimentos & MNCT & Rede farmiliar de supermercados que passou a adotar práticas circulares nos últimos anos & 2018 \\
\hline 16 & Energia & $\mathrm{MNCN}$ & $\begin{array}{l}\text { Empresa que realiza a coleta de } \mathrm{CO} 2 \text { e calor de processos industriais e os converte em energia, } \\
\text { que é oferecida na forma de servico para pequenos agricultores locais }\end{array}$ & 2019 \\
\hline 17 & Produtos eletrônicos & MNCT & $\begin{array}{l}\text { Empresa de produtos eletrônicos (impressoras e câmeras digitais) que passou a adotar práticas } \\
\text { circulares ao longo de seus processos produtivos nas últimas décadas. }\end{array}$ & 2018 \\
\hline 18 & $\begin{array}{l}\text { Serviços de reciclagem, } \\
\text { restauração e gestão de } \\
\text { resíduos }\end{array}$ & $\mathrm{MNCN}$ & $\begin{array}{l}\text { Empresa voltada à pesquisa, desenvolvimento e comercialização de tecnologias e processos } \\
\text { industriais de AHP ("absorbert hygiene products") }\end{array}$ & 2021 \\
\hline 19 & Material de escritório & $\mathrm{MNCN}$ & $\begin{array}{l}\begin{array}{l}\text { Emquresa que produz materiais de escritório (canetas, lápis e cadernos) a partir de matérias-primas } \\
\text { virgens, naturais e materiais reciclados }\end{array} \\
\end{array}$ & 2020 \\
\hline 20 & Têxti1 & $\mathrm{MNCN}$ & $\begin{array}{l}\text { Marca de roupas cujos produtos são feitos a partir de restos de tecidos ou de materiais } \\
\text { biodegradáveis }\end{array}$ & 2020 \\
\hline 21 & Agronegócio & MNCT & $\begin{array}{l}\text { Consórcio do ramo de "agrobusiness" que passou a adotar práticas de processamento, } \\
\text { reutilizacáa e reciclagem do desperdício de carne ao longo da cadeia produtiva }\end{array}$ & 2021 \\
\hline 22.1 & $\begin{array}{l}\text { Serviços de reciclagem, } \\
\text { restauração e gestão de } \\
\text { resíduos }\end{array}$ & $\mathrm{MNCN}$ & $\begin{array}{l}\text { Empresa que opera na reciclagem e restauração de produtos eletrônicos e tecnológicos, os quais } \\
\text { são destinados a mercados de segunda măo posteriormerte }\end{array}$ & \multirow[b]{2}{*}{2019} \\
\hline 22.2 & $\begin{array}{l}\text { Serviços de reciclagem, } \\
\text { restauração e gestão de } \\
\text { resíduos }\end{array}$ & $\mathrm{MNCN}$ & $\begin{array}{l}\text { Empresa que desenvolve produtos inovadores a partir da reutilização de componentes químicos } \\
\text { da borracha e plástico }\end{array}$ & \\
\hline 23 & $\begin{array}{l}\text { Serviços de reciclagem, } \\
\text { restauração e gestão de } \\
\text { resíduos }\end{array}$ & $\mathrm{MNCN}$ & $\begin{array}{l}\text { Empresa que oferece serviços de coleta de dejetos de cavalos criados em estábulos e os } \\
\text { encaminham para uma usina que os transfomam em eletricidade e calor }\end{array}$ & 2019 \\
\hline 24 & Energia & MNCT & $\begin{array}{l}\text { Empresa que tem como foco a exploração de óleo e gás natural e que tem se voltado à produçäo } \\
\text { de fontes de energia renováveis em plantas especificas }\end{array}$ & 2020 \\
\hline 25 & Têxtil & MNCT & $\begin{array}{l}\text { Marca de roupas que passou a produzir toda a sua linha de roupa de banho a partir de fibras } \\
\text { recicladas, comopet e polimeros semelhantes }\end{array}$ & 2019 \\
\hline
\end{tabular}

FIGURA 4 - Identificação dos estudos de caso utilizados para a análise. Fonte: elaborado pelo autor 
Para cada um dos 31 casos selecionados foram mapeados até $4 \mathrm{FS}$, os quais foram classificados em uma das 6 dimensões adaptadas de Aloini et al. (2020). Os casos também foram classificados de acordo com o nível de adoção dos princípios da EC pelos MNC, conforme a proposição de Rovanto e Bask (2021): MNC Nativos (MNCN) e MNC em Transição (MNCT). A figura 5 representa o número de FS identificados por dimensão.

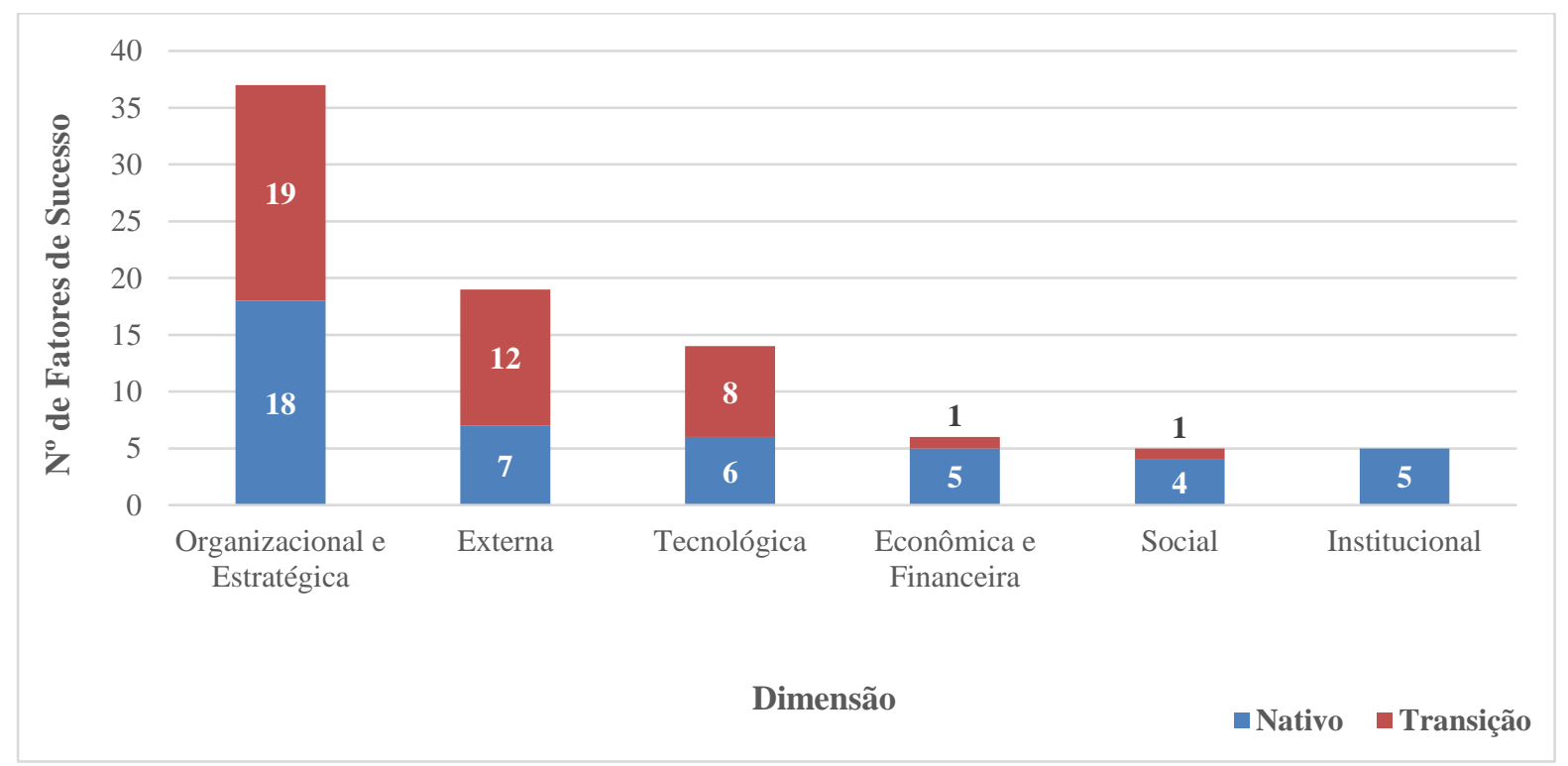

FIGURA 5 - Distribuição dos Fatores de Sucesso de acordo com as suas dimensões. Fonte: elaborado pelo autor

\section{Dimensão "Organizacional e Estratégica"}

Esta dimensão foi a mais representativa, contemplando 37 dos 86 FS mapeados. Os FS desta dimensão se mostraram relevantes tanto para os MNCN (18) quanto para os MNCT (19), e estão distribuídos de acordo com as subdimensões representadas na figura 6. 


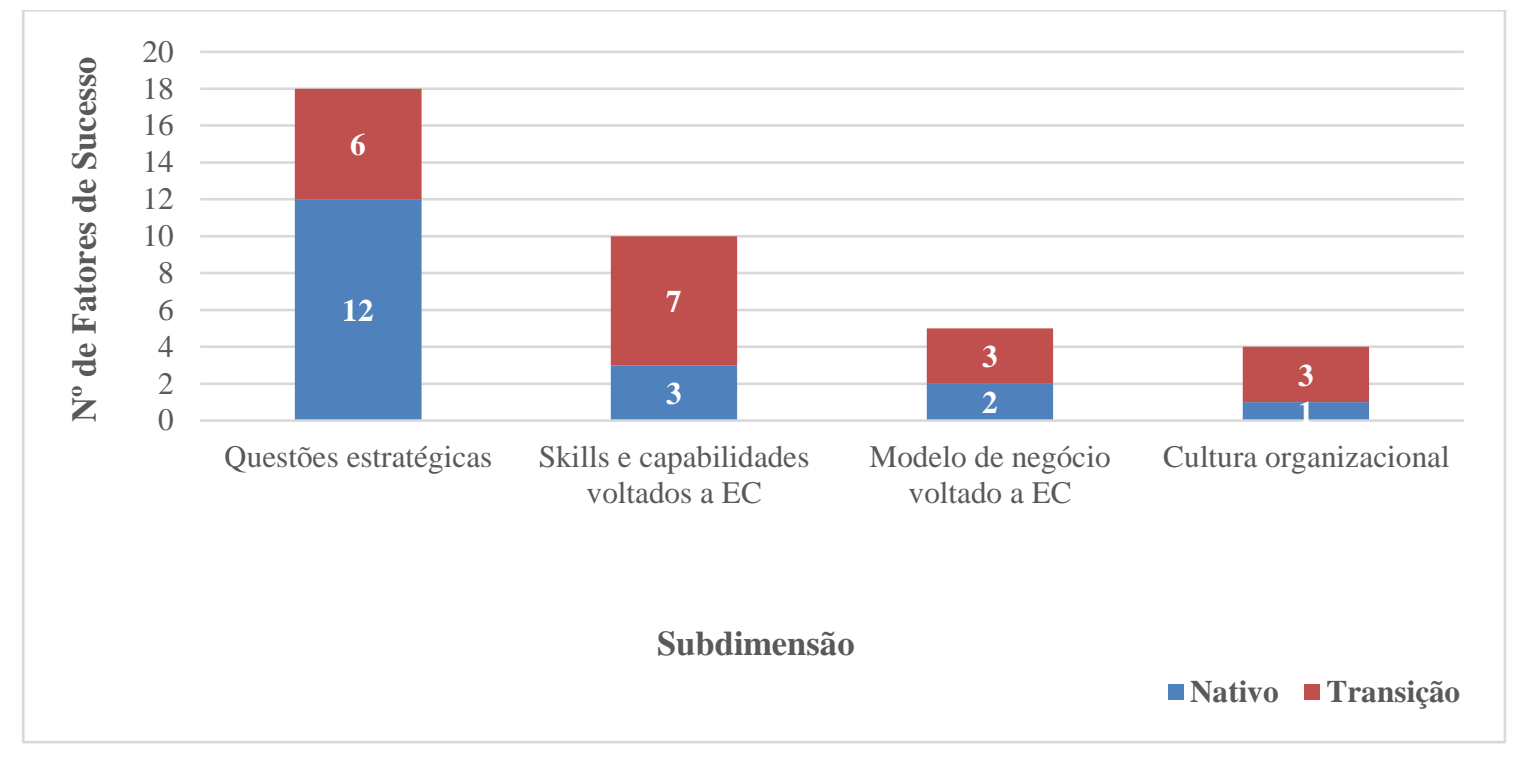

FIGURA 6 - Fatores de Sucesso pertencentes à dimensão “Organizacional e Estratégica”. Fonte: elaborado pelo autor

Os FS de maior frequência desta dimensão pertencem à subdimensão "Questões estratégicas". O FS “qualidade dos produtos e serviços circulares oferecidos" pôde ser identificado em 8 casos diferentes. No caso de ID 1, por exemplo, o design de uma linha de roupas remanufaturadas baseado no uso mínimo de acessórios (adereços, botões e zíperes) fez com que a vida útil dos produtos confeccionados fosse estendida. O FS "estratégia corporativa com foco na EC" pôde ser identificado em 5 casos diferentes, sendo 4 deles MNCN, o que pode indicar que este FS é mais comumente encontrado em MNC seguem os princípios da EC desde a sua fundação. Nos casos ID 8 (setor de turismo) e 20 (setor têxtil), a estratégia adotada pelos MNC foi o investimento em plataformas digitais, o que facilitou a comunicação dos valores e crenças voltados a EC das empresas aos consumidores, além de consolidar o $e$ commerce como os seu principal canal de venda. Para Lewandowski (2016), uma das maiores mudanças relacionadas à adoção de MNC é a virtualização dos canais de venda; isto é, uma organização pode vender uma proposta de valor virtual e entregá-la virtualmente (produtos digitais) ou vender uma proposta de valor através de canais virtuais (e-commerces).

Ainda na nesta subdimensão, foi possível identificar o FS "potencial de diferenciação" em 4 casos diferentes, todos eles classificados como MNCN, o que pode indicar que MNC que adotam os princípios da EC desde a sua origem possuem maior facilidade em criarem propostas de valor diferenciadas e pouco encontradas nos seus respectivos setores de mercado. No caso de ID 8, por exemplo, um MNC garantiu o seu 
sucesso através de ofertas e pacotes personalizados para clientes que estão em busca da realização de turismo ecológico.

Foram identificados 10 FS na subdimensão "Skills e capabilidades voltados a EC", sendo 7 delas referentes a MNCT. O FS "know-how da organização e dos colaboradores" foi identificado em 4 casos. No ID 10, uma empresa da indústria de calçados, as experiências anteriores dos empreendedores que fundaram a empresa com outros MNC garantiram o seu sucesso no mercado. Outros 4 casos apresentaram o "treinamento e educação voltados a EC" como um FS. Todos os casos são MNCT, o que pode revelar uma maior necessidade de treinamentos e desenvolvimento de capabilidades em empresas que começaram a adotar práticas circulares depois de sua fundação. No caso de ID 4, por exemplo, uma empresa que tem como core business o oferecimento de serviços de reciclagem e tratamento de água e solo passou a fornecer treinamentos obrigatórios sobre EC para os seus colaboradores.

O último FS identificado nesta subdimensão foi o "envolvimento e motivação dos colaboradores em relação a EC e sustentabilidade" no caso de ID 6, um MNC que utiliza restos de alimentos e efluentes domésticos para produzir fertilizantes agrícolas. Para Mattos e Albuquerque (2018), a mentalidade e comprometimento dos colaboradores são aspectos importantes na facilitação da transição para um modelo de EC.

A subdimensão "Modelo de negócio voltado a EC" foi identificada em 5 casos diferentes: nos casos 14 e 19, a "intensificação do "green marketing" foi considerada um FS que possibilitou que os MNC intensificassem a divulgação de seus produtos e serviços associando os seus benefícios ao meio ambiente. Essa mesma subdimensão contempla o "sistema de gestão e certificação voltado a EC e sustentabilidade" como um FS, identificado em 3 casos. No caso de ID 22.1, o sistema de gestão e certificação adotado possibilitou a padronização, controle e adaptação dos processos da companhia aos princípios da EC.

A subdimensão "Cultura organizacional" foi identificada em 4 casos. Em todos, o FS identificado foi a "cultura e consciência corporativa voltadas a EC e sustentabilidade". No caso de ID 17, a disseminação de uma cultura corporativa voltada à construção de capabilidades voltadas aos princípios da EC foi um dos fatores que levou a companhia a alcançar o sucesso.

\section{Dimensão "Externa"}


Esta dimensão foi a segunda mais representativa, contemplando 19 dos 86 FS identificados. A figura 7 representa graficamente os FS da dimensão em questão, que se mostraram mais relevantes para MNCT (12) do que para os MNCN (7).

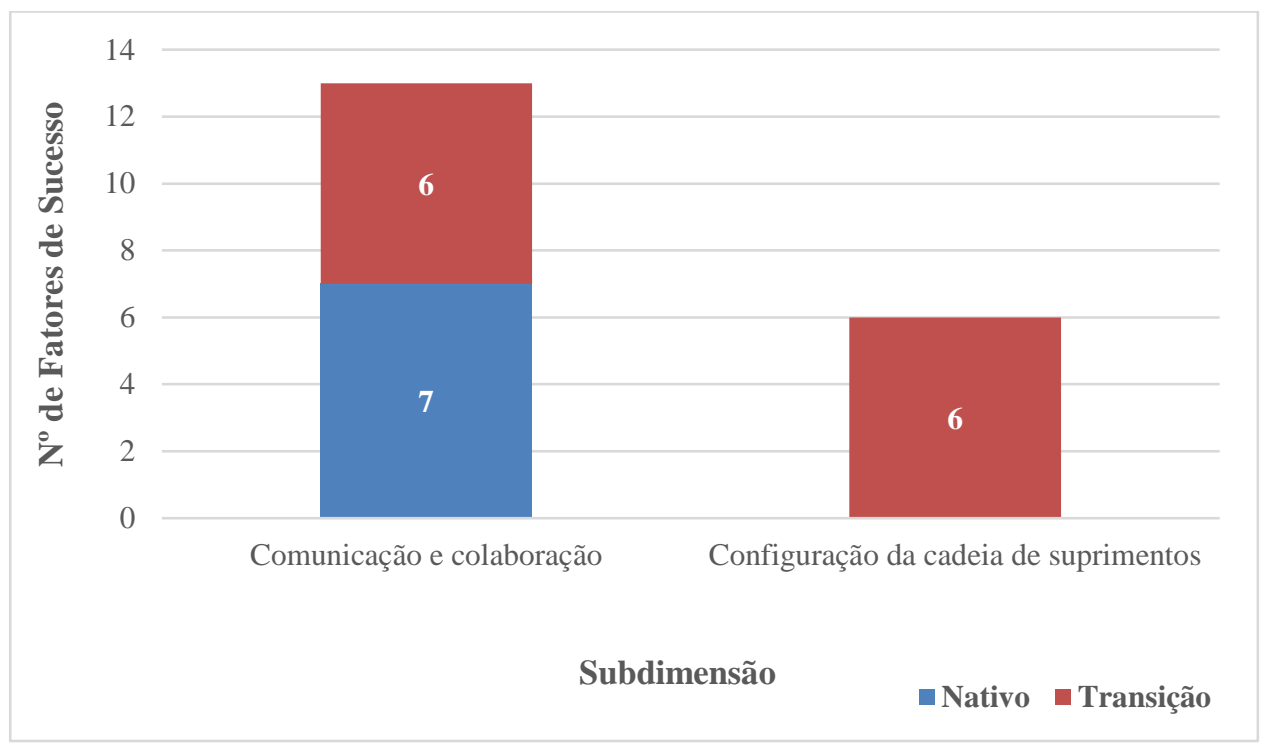

FIGURA 7 - Fatores de Sucesso pertencentes à dimensão "Externa". Fonte: elaborado pelo autor

Os FS de maior frequência pertencem à subdimensão "Comunicação e colaboração", representando um total de 13 ocorrências. O FS “colaboração, parceria ou coordenação com stakeholders externos através de networking ou compartilhamento de informações" foi mapeado em 12 casos. Para Antikainen e Valkokari (2016), os MNC são, por natureza, estruturados em rede: eles requerem colaboração, comunicação e coordenação de redes complexas e interdependentes.

No caso de ID 5.3, a colaboração e troca de informações entre as franquias de um MNC de self-service de lavagem de roupas foi essencial para o entendimento do comportamento dos clientes e adoção das melhores práticas. Já no caso de ID 22, um MNC que é um dos maiores consórcios de agronegócio polonês, a base forte de clientes e a boa relação com eles facilitou o escoamento periódico da produção sob demanda.

Outro FS mapeado foi "práticas de comunicação", presente apenas no caso de ID 19, em que um MNC que vende produtos de material de escritório reciclados, criou uma estratégia de transmissão dos valores da empresa aliados aos princípios da EC através de múltiplos canais de comunicação: produto, vendedores, mídias sociais, propagandas, entre outros. 
Na subdimensão "Configuração da cadeia de suprimentos" foram mapeados 7 FS, todos classificados como MNCT. A "integração da cadeia de suprimentos" foi identificada em 3 casos: no ID 17, por exemplo, uma empresa de produtos eletrônicos passou a adotar práticas de coleta, restauração e/ou descarte correto dos seus componentes eletrônicos, que só foi possível através da integração de cada uma das partes da cadeia de suprimentos do MNC.

Os "múltiplos canais de distribuição" foi um FS identificado em 2 casos. No ID 1, a grande quantidade de lojas físicas de uma grife de roupas favoreceu a escalabilidade de um sistema de coleta de roupas que não são mais usadas pelos clientes da marca e que são restauradas para que possam ser revendidas posteriormente.

Por fim, o FS “capacidade de interconexão possibilitada pela proximidade geográfica" também foi identificado nesta subdimensão, exclusivamente no caso de ID 4: uma empresa do setor de serviços de gestão de resíduos garantiu o seu sucesso pelo fato das estações de tratamento dos efluentes estarem localizadas próximas às fontes de despejo.

\section{Dimensão "Tecnológica"}

Nesta dimensão foram identificados 14 FS, que se mostraram relevantes tanto para MNCN (6) quanto para MNCT (8), ilustrado na figura 8.

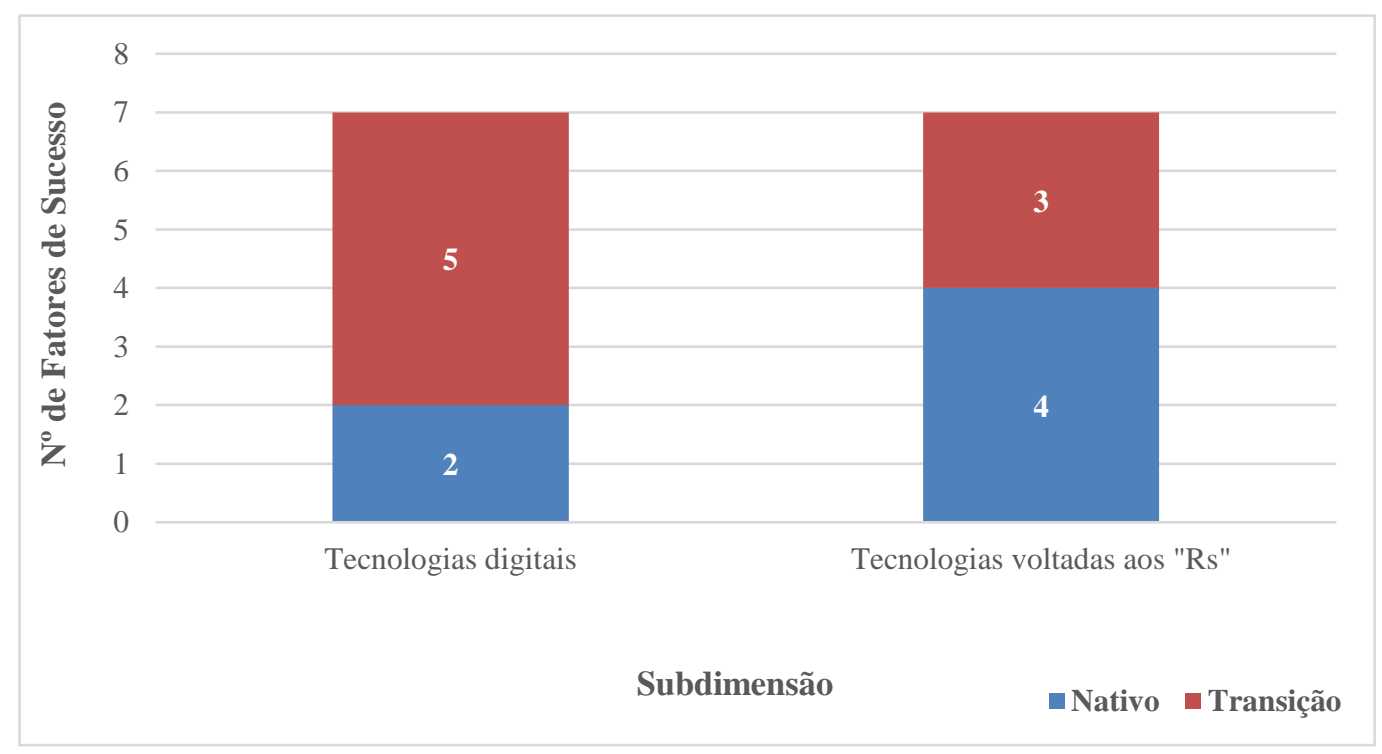

FIGURA 8 - Fatores de Sucesso pertencentes à dimensão “Tecnológica”. Fonte: elaborado pelo autor 
Para Mattos e Albuquerque (2018), as companhias precisam planejar as suas infraestruturas de Tecnologia da Informação (TI) visando criar plataformas colaborativas que permitam a conexão com diferentes agentes nos ambientes externos, como resolvedores de problemas ou criadores de novas ideias e soluções.

Na subdimensão "Tecnologias digitais", foram mapeados 7 FS. O fator "tecnologias digitais da informação e comunicação" foi identificado 3 vezes: no ID 3, um MNC global voltado a sistemas, produtos e serviços digitais, ao desenvolver um software que facilita o controle e visualização das atividades da planta industrial, obteve maior eficiência material, maior economia de energia e constatou redução do consumo de matéria-prima.

O FS "Internet das coisas (IoT)" foi identificado em 4 casos: no ID 9, uma empresa global do setor automobilístico adotou os princípios da IoT para mapear a necessidade de manutenção das peças e levantar estatísticas relevantes dos veículos de seus clientes. Através da manutenção preditiva, a empresa aumentou a vida útil dos veículos comercializados, além de registrar redução nas taxas de problemas técnicos e acidentes.

O FS “automação” foi encontrado no caso de ID 14, no qual uma empresa da indústria de joias conseguiu elevar os níveis de automação do processo produtivo e diversificar o seu portfólio de produtos a partir do momento em que passou a utilizar impressoras 3D.

A segunda subdimensão está relacionada às “Tecnologias voltadas aos 3Rs", que faz menção ao FS "produtos tecnológicos e processos inovadores voltados à redução, reciclagem ou reutilização de produtos e materiais”. Para Bianchini et al. (2018), a integração entre tecnologias digitais emergentes, favorecida pela EC, possibilita que as companhias tenham a oportunidade de escolher um MNC inovador e mais produtivo.

Este FS foi identificado em 7 casos: no caso de ID 13.1, uma empresa que oferece soluções de logística reversa para a indústria de eletrodomésticos de linha branca adotou tecnologias inovadoras no processo de desmanche e reciclagem dos componentes recebidos, aumentando a sua eficiência e facilitando o processo de destinação correta de materiais a serem descartados. Já no caso ID 22.2, a criação de um método inovador possibilitou a produção de uma matéria-prima substituta a derivados do petróleo feita a partir de pneus usados e outras sucatas de borracha, cujo processo produtivo consome menos água e energia elétrica, além de emitir menos $\mathrm{CO} 2$ na atmosfera.

\section{Dimensão "Econômica e Financeira"}


Foram identificados 6 FS nesta dimensão, a qual se mostrou mais relevante para MNCN, que representam 5 dos $6 \mathrm{MNC}$ identificados nesta categoria, conforme ilustrado na figura 9.

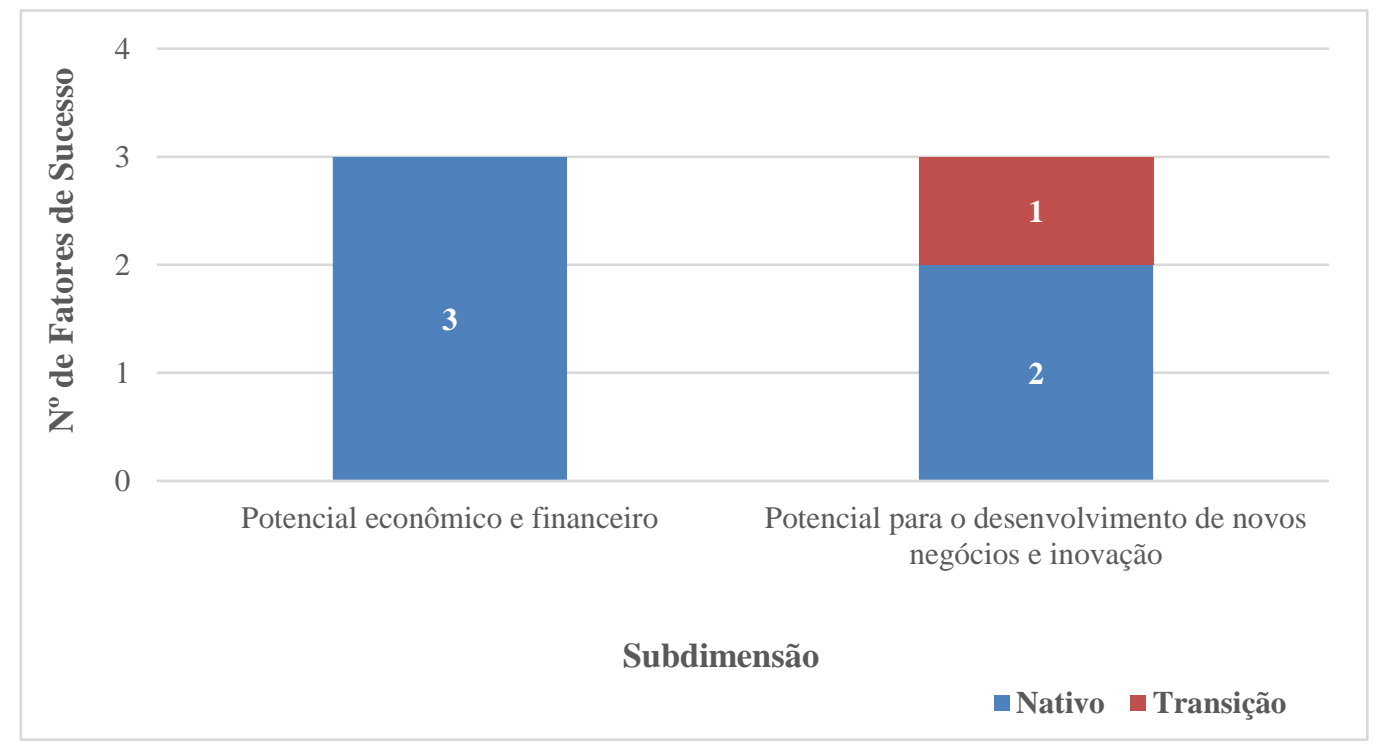

FIGURA 9 - Fatores de Sucesso pertencentes à dimensão "Econômica e Financeira". Fonte: elaborado pelo autor

Na subdimensão "Potencial econômico e financeiro", 2 casos apresentaram o "acesso a financiamento privado" como FS. No caso ID 8, a companhia teve acesso a um programa de financiamento privado durante a fase de idealização, o que garantiu a estruturação e consolidação no mercado a médio prazo. Já no caso ID 22.2, investidores anjos apostaram no sucesso do MNC e realizaram aportes financeiros que alavancaram as operações e garantiram ganhos de escala para os produtos oferecidos pela empresa.

A "consistência entre geração de receita/redução de custos e investimentos necessários" foi um FS identificado no caso ID 5.1: neste $\mathrm{MNC}$, máquinas de lavar são alugadas pelos clientes como forma de serviço, cobrado através de uma assinatura mensal e por ciclo de lavagem: este sistema "pay per use" garantiu o sucesso financeiro da empresa a longo prazo.

Já na subdimensão "Potencial para o desenvolvimento de novos negócios e inovação", 3 casos apresentaram o FS “criação de novas percepções de valor": no caso ID 7.3, o sucesso foi possibilitado pela sua forma não convencional de gerar valor através de um modelo de serviço "pay per lux", no qual os clientes não compram produtos, mas sim contratam uma 
assinatura de sistema de iluminação no qual já estão inclusos os serviços de instalação, manutenção e reparo.

\section{Dimensão "Social"}

Ao todo, conforme ilustrado pelo gráfico da figura 10, foram identificados 5 FS nessa dimensão, que se mostraram mais relevantes para MNCN (4 no total) do que para MNCT (1 no total):

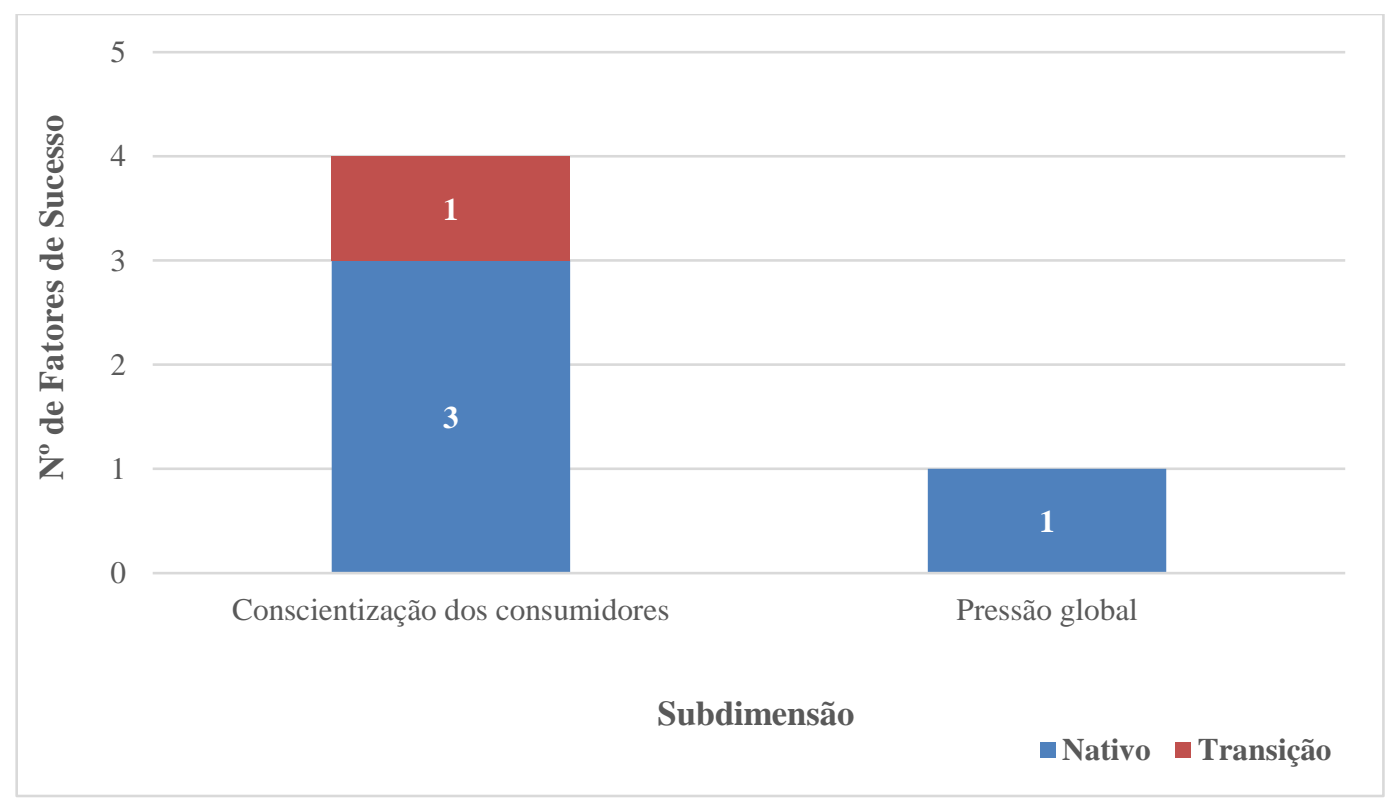

FIGURA 10 - Fatores de Sucesso pertencentes à dimensão "Social”. Fonte: elaborado pelo autor

Ao todo, em relação à subdimensão "Conscientização dos consumidores", todos os 4 casos mapeados apresentaram a "consciência acerca da EC e sustentabilidade" como um FS. No caso 22.1, por exemplo, a conscientização dos consumidores acerca dos impactos ambientais causados pelo descarte incorreto de componentes de equipamentos eletrônicos favoreceu a aceitação do serviço proposto pela empresa em questão: a reciclagem ou restauração de produtos eletrônicos/tecnológicos descartados.

Em relação à subdimensão "Pressão global", o caso de ID 23 apresentou a "pressão voltada a práticas verdes e mais sustentáveis vindas de entidades públicas, competidores e sociedade" como um FS, já que os clientes da empresa passaram a contratar o serviço oferecido como forma de se promoverem em meio a competidores e sociedade. 


\section{Dimensão "Institucional”}

Conforme representado pelo gráfico da figura 11, esta dimensão de FS se mostrou relevante apenas para $\mathrm{MNCN}$, classificação dada a todos os MNC mapeados nesta categoria.

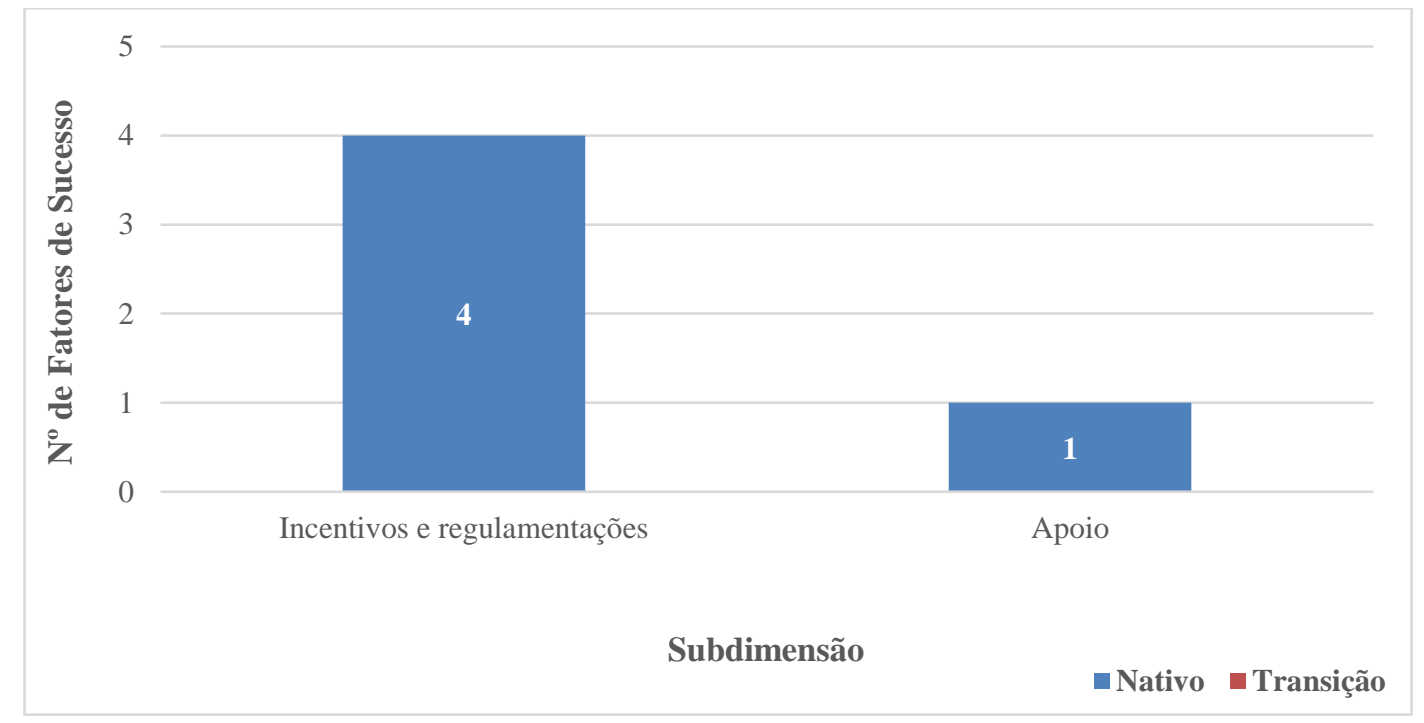

FIGURA 11 - Fatores de Sucesso pertencentes à dimensão "Institucional”. Fonte: elaborado pelo autor

Na subdimensão "Incentivos e regulamentações", 4 casos apresentaram as "políticas, leis, diretivos e regulamentações" como um FS de seus MNC. No caso de ID 2, as legislações relacionadas ao desperdício do país em questão garantiram o sucesso das soluções de reutilização e reciclagem de produtos de bens de consumo oferecidas pela empresa. Já no caso de ID 13.1, um dos fatores que levou o MNC a obter sucesso foi a existência de uma política nacional de resíduos sólidos, favorecendo a implementação de soluções inovadores de logística reversa por parte da empresa em questão.

Já na subdimensão "Apoio", o caso de ID 16 apresentou o "financiamento e empréstimos governamentais a juros baixos" como um de seus FS: os investimentos financeiros do governo local foram essenciais para o desenvolvimento inicial do negócio, que oferece como serviço principal a coleta de $\mathrm{CO} 2$ e calor residual de companhias industriais e os transforma em novas fontes de energia para agricultores locais.

\section{CONCLUSÃO}

O presente trabalho cumpre o seu objetivo principal em identificar os principais fatores que garantem o sucesso de Modelos de Negócios Circulares, através da aplicação de 
uma RBS, que possibilitou a seleção de estudos de caso de sucesso pertencentes a diversos contextos geográficos e de setor de mercado. Este estudo possibilitou a sintetização do resultado da aplicação prática dos princípios da Economia Circular em Modelos de Negócios pertencentes a diferentes níveis de maturidade.

Além disso, em alguns casos, foi possível notar diferenças e tendências entre os resultados apresentados por Modelos de Negócios que aplicam os princípios da EC desde a sua fundação (MNCN) e aqueles que passaram a aplicar os princípios da EC a partir de um momento específico (MNCT).

Para estudos futuros com temáticas que se relacionam com os objetivos desta pesquisa, recomenda-se que as análises sejam feitas a partir de segmentações e contextos mais delimitados, restringindo aspectos dos Modelos de Negócios Circulares como localização geográfica, setor de mercado e nível de maturidade.

\section{REFERÊNCIAS}

ALOINI, D. et al. Driving the transition to a circular economic model: a systematic review on drivers and critical success factors in circular economy. Sustainability, v.12, n.24, Dec. 2020. DOI: https://doi.org/10.3390/su122410672.

ANTIKAINEN, M.; VALKOKARI, K. A Framework for sustainable circular business model innovation. Technology Innovation Management Review, v. 6, n. 7, p. 5-12, 2016.

BIANCHINI, A. et al. A New productive model of circular economy enhanced by digital transformation in the fourth industrial revolution - an integrated framework and real case studies. In: SUMMER SCHOOL "FRANCESCO TURCO" - INDUSTRIAL SYSTEMS ENGINEERING, 23., 2018, Palermo. Proceedings [....]. Roma: AIDI, 2018. p.221-227.

CENTOBELLI, P. et al. Designing business models in circular economy: a systematic literature review and research agenda. Business Strategy and Environment, v.29, n.4, p. 734-1749, May 2020.

CONFORTO, E. C.; AMARAL, D. C.; SILVA, S. L. Roteiro para revisão bibliográfica sistemática: aplicação no desenvolvimento de produtos e gerenciamento de projetos. In: CONGRESSO BRASILEIRO DE GESTÃO DE DESENVOLVIMENTO DE PRODUTO, 8., 2011, Porto Alegre. Anais [...]. Porto Alegre: UFRGS, 2011.

MATTOS, C. A.; ALBUQUERQUE, T. L. M. Enabling factors and strategies for the transition toward a circular economy (CE). Sustainability (Switzerland), v. 10, n. 12, 2018. DOI: https://doi.org/10.3390/su10124628.

DEL VECCHIO, P. et al. Circular economy business model for smart tourism: the case of Ecobnb. EuroMed Journal of Business, 2021. DOI: 10.1108/EMJB-09-2020-0098.

LEWANDOWSKI, M. Designing the business models for circular economy — towards the conceptual framework. Sustainability, v.8, n.1, 2016. DOI: https://doi.org/10.3390/su8010043.

OKOLI, C. A Citation analysis of theoretical concept reviews. In: AMERICAS CONFERENCE ON INFORMATION SYSTEMS, 25., 2019, Cancún. Proceedings [...]. [S.1.]: Association for Information Systems, 2019.

PIERONI, M. P. P.; MCALOONE, T. C.; PIGOSSO, D. C. A. Business model innovation for circular economy and sustainability: a review of approaches. Journal of Cleaner Production, v. 215, p. 198-216, 2019.

ROVANTO, I. K.; BASK, A. Systemic circular business model application at the company, supply chain and society levels - a view into circular economy native and adopter companies. Business Strategy and the Environment, v. 30, n. 2, p. 1153-1173, 2021. 